\title{
Earth after the Moon-forming Impact
}

\section{K.J. ZAHNLE ${ }^{1}$}

${ }^{1}$ NASA Ames Research Center ; kzahnle@mail.arc.nasa.gov

The Hadean Earth is widely and enduringly pictured as a world of exuberant volcanism, exploding meteors, huge craters, infernal heat, and billowing sulfurous steams; i.e., a world of fire and brimstone punctuated with blows to the head. In the background the Moon looms gigantic in the sky. The popular image has given it a name that celebrates our mythic roots. A hot early Earth is an inevitable consequence of accretion. The Moon-forming impact ensured that Earth as we know it emerged from a fog of silicate vapor.

The impact separated the volatiles from the silicates. It took $\sim 100$ years to condense and rain out the bulk of the vaporized silicates, although relatively volatile elements may have remained present in the atmosphere throughout the magma ocena stage. The magma ocean lasted $\sim 2 \mathrm{Myr}$, its lifetime prolonged by tidal heating and thermal blanketing by a thick $\mathrm{CO}_{2}$-rich steam atmosphere. Water oceans condensed quickly after the mantle solidified, but for some 10-100 Myr the surface would have stayed warm $(-500 \mathrm{~K})$ until the $\mathrm{CO}_{2}$ was removed into the mantle. Thereafter the faint young Sun suggests that a lifeless Earth would always have been evolving toward a bitterly cold ice world, but the cooling trend was frequently interrupted by volcanic or impact induced thaws.

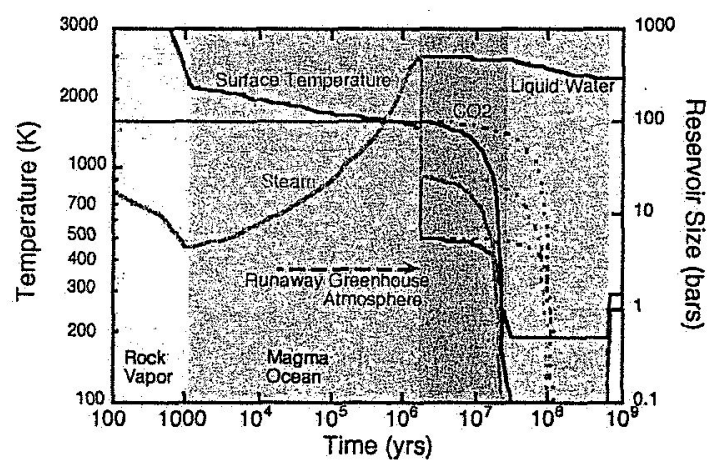

A cartoon history of water, temperature, and carbon dioxide in the aftermath of the moon-forming impact. How long it stays hot depends on how long it takes to scrub the $\mathrm{CO}_{2}$ out of the atmosphere. 